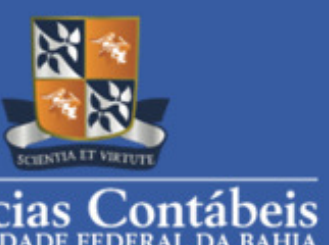

DOI: http://dx.doi.org/10.9771/rc-ufba.v14i3.35423

\title{
INFLUÊNCIA DAS CONEXÕES POLÍTICAS NO CUSTO DE FINANCIAMENTO DA DÍVIDA DAS COMPANHIAS ABERTAS LISTADAS NA B3
}

\author{
INFLUENCE OF POLITICAL CONNECTIONS ON THE DEBT FINANCING \\ COST OF PUBLICLY TRADED COMPANIES LISTED ON B3
}

Geovanne Dias de Moura ${ }^{1}$

FGK Empreendimentos Educacionais

geomoura@terra.com.br

\section{Sady Mazzioni}

Universidade Comunitária da Região de

Chapecó - UNOCHAPECÓ

sady@unochapeco.edu.br

\author{
Aline Luiza Brusco Pletsch \\ Universidade Comunitária da Região de \\ Chapecó - UNOCHAPECÓ \\ aline_b@unochapeco.edu.br
}

\author{
Neusa Maria Gonçalves Salla \\ Universidade Regional Integrada do Alto \\ Uruguai e Missões - URI \\ neusalla@san.uri.br
}

\author{
Antonio Zanin \\ Universidade Comunitária da Região de Chapecó - UNOCHAPECÓ \\ zanin@unochapeco.edu.br
}

\begin{abstract}
RESUMO
O estudo verificou a influência das conexões políticas no custo de financiamento da dívida de companhias abertas listadas na B3. Realizou-se pesquisa descritiva, quantitativa e documental, com consulta aos Formulários de Referência, banco de dados Economática, website do TSE e Asclaras. O custo da dívida foi analisado pela razão entre as despesas financeiras e o passivo oneroso. Para conexões políticas foram utilizadas três variáveis: (1) dummy para doações às campanhas eleitorais; (2) dummy para participação acionária direta ou indireta do governo na estrutura de propriedade das empresas; (3) dummy para doações às campanhas eleitorais ou participação acionária do governo. Os resultados indicaram que as médias do custo do endividamento eram estatisticamente inferiores, na maioria dos anos, somente no grupo de empresas que realizaram doações às campanhas eleitorais. A análise multivariada confirmou que as conexões políticas por meio de doações para campanhas eleitorais influenciavam para a redução do custo da dívida.
\end{abstract}

Palavras-chave: Conexões políticas. Custo de financiamento da dívida. Companhias abertas.

\footnotetext{
${ }^{1}$ Rua Maria Selma Vasconcelos Carneiro, 539 - Bairro Renato Parente - Sobral/CE - CEP: 62.033-025
}

Recebido em 07/02/2020. Revisões requeridas em 14/09/2020. Aceito em 09/10/2020. Publicado em 30/12/2020. 


\begin{abstract}
The study looked at the influence of political connections on the debt financing cost of publicly traded companies listed on B3. Descriptive, quantitative and documentary research was carried out, with reference to the Reference Forms, Economática database, TSE website and Asclaras. The cost of debt was analyzed using the ratio between financial expenses and interestbearing liabilities. For political connections, three variables were used: (1) dummy for donations to election campaigns; (2) dummy for direct or indirect government participation in the ownership structure of companies; (3) dummy for donations to election campaigns or government shareholding. The results indicated that the average cost of debt was statistically lower, in most years, only in the group of companies that made donations to election campaigns. The multivariate analysis confirmed that political connections through donations to election campaigns influenced the reduction in the cost of debt.
\end{abstract}

Keywords: Political connections. Cost of debt financing. Publicly traded company.

\title{
1 INTRODUÇÃO
}

De modo geral, há consenso na literatura (SHAILER; WANG, 2015; DERRIEN; KECSKÉS; MANSI, 2016; ARDALAN, 2017; GHOUMA; BEN-NASR; YAN, 2017; LE; $\mathrm{BICH}, 2017)$ de que os financiamentos são uma forma importante que as empresas possuem para obter recursos. Então, diante da importância do assunto, pesquisadores têm procurado identificar fatores que influenciam no custo da dívida, sendo que as conexões políticas são um desses fatores.

As conexões políticas referem-se às ligações existentes entre empresas e ou grupos econômicos e os governos. Tais conexões podem ocorrer por meio de doações das empresas para campanhas eleitorais (COSTA; BANDEIRA-DE-MELLO; MARCON, 2013; MACÊDO; SILVA; MACHADO, 2015; SENA et al., 2016; SILVA, 2016), participação acionária do governo na estrutura de propriedade das empresas (BOUBAKRI et al., 2012; BORISOVA et al., 2015; SHAILER; WANG, 2015; SANTOS, 2017), ou pela atuação de políticos ou expolíticos nos conselhos de administração e na diretoria executiva das empresas (FACCIO, 2006; HOUSTON et al., 2014; DING; LI; WU, 2018), por exemplo.

$\mathrm{Na}$ literatura, estudos vem identificando benefícios mútuos nessa relação empresagoverno, tais como informação privilegiada, influência, proteção, recursos financeiros e rendas (PITTMAN, 1977; MAHON, MURRAY, 1981; HILLMAN, KEIM, 1995; FISMAN, 2001). Especificamente às empresas, podem proporcionar benefícios como acesso preferencial a financiamentos bancários de melhor condição, recebimento de subvenções e assistências governamentais, maiores chances de vencer concorrentes para compras governamentais e menor pressão regulatória. Todos estes fatores podem contribuir para um aumento da vantagem competitiva, do desempenho e do valor das empresas que, consequentemente, resultará em aumento de credibilidade perante os fornecedores da dívida que poderão fornecer recursos a um custo inferior (BOUBAKRI et al., 2012; HOUSTON et al., 2014; SHAILER; WANG, 2015; HUNG et al., 2017).

Por outro lado, a existência de conexões poderia resultar em maior propensão das empresas na busca por objetivos políticos, como fornecer empregos desnecessários, empregar políticos não qualificados em cargos diversos, ou, aumentar salários de colaboradores politicamente conectados. Também poderia aumentar a relutância em iniciar demissões de funcionários para reduzir custos operacionais. Estes fatores retiram o foco da maximização do 
valor e prejudicam o desempenho, afetando, inclusive, o custo de financiamento da dívida que poderia se elevar em razão de uma má gestão (JACKOWICZ; KOZLOWSKI; MIELCARZ, 2014; LIEDONG; RAJWANI, 2017).

No tocante aos estudos sobre a influência das conexões políticas no custo de financiamento da dívida, os resultados ainda não apresentam aspectos que possibilitem uma conclusão precisa sobre como as empresas são beneficiadas, se são beneficiadas e em quais contextos. Pois, enquanto alguns pesquisadores, tais como Boubakri et al. (2012), Houston et al. (2014), Shailer e Wang (2015) e Santos (2017) constataram que empresas com conexões políticas apresentavam menor custo de financiamento da dívida, outros pesquisadores, como Bliss e Gul (2012), Borisova et al. (2015), Silva (2016) e Liedong e Rajwani (2017), verificaram que empresas com conexões políticas apresentavam maior custo de financiamento da dívida.

Então, desse contexto surge a questão problema que norteia esta pesquisa: Qual a influência das conexões políticas no custo do financiamento da dívida de companhias abertas listadas na B3? Assim, o estudo objetiva verificar a influência das conexões políticas no custo de financiamento da dívida de companhias abertas listadas na B3.

O estudo contribui com a literatura existente que aborda a importância das relações políticas entre empresas e poder público. Borisova et al. (2015) descrevem que a influência das conexões políticas sobre o custo da dívida é especialmente complexa, uma vez que os governos podem tentar impor às empresas objetivos sociais e políticos, mas, por outro lado, também oferecem benefícios implícitos que podem resultar em vantagens importantes. Em razão desses aspectos conflitantes e do papel predominante da dívida no financiamento corporativo, tornase relevante investigar o impacto que as conexões podem causar sobre o custo da dívida em empresas brasileiras.

É importante ressaltar também que as conexões políticas são mais propícias em países de economia menos desenvolvida, ou, em governos com mais discricionariedade na alocação de recursos (CHEN et al., 2011). Logo, o Brasil se encaixa nesse contexto e, em virtude de as eleições brasileiras demandarem recursos financeiros vultuosos, principalmente quando se compara o Brasil com outras nações, as empresas tornam-se importantes financiadoras de recursos para políticos alcançarem objetivos de disputas eleitorais (CAMILO, MARCON, BANDEIRA-DE-MELLO, 2012).

\section{CONEXÕES POLÍTICAS E CUSTO DE FINANCIAMENTO DA DÍVIDA}

As conexões políticas podem ser definidas como ligações que ocorrem principalmente entre empresas e políticos, em que ambas as partes visam atingir determinados objetivos. Camilo, Marcon e Bandeira-de-Mello (2012) especificam a conexão política como uma prática realizada por organizações que desejam, na maioria das vezes, obter recursos e maiores facilidades para alcançar os objetivos e, no que concerne aos políticos, o interesse reside com prioridade nos financiamentos às campanhas eleitorais. No Brasil, essas conexões são antigas, tendo início por volta de 1930, quando os empresários resolveram financiar a campanha eleitoral de Getúlio Vargas para presidente do país (BAZUCHI et al., 2013).

De modo geral, a conexão pode ser caracterizada por um contrato informal, em que uma empresa patrocina a campanha eleitoral e contribui para aumentar as chances de vitória dos políticos frente a um pleito eleitoral. Neste caso, os políticos, caso vençam as eleições, comprometer-se-iam, de alguma maneira, a compensar tal contribuição eleitoral (CORREIA, 2014). Na literatura, o que se evidencia é que as conexões políticas, muitas vezes, contribuem para o desenvolvimento das empresas, possibilitando melhores condições para aquisição de empréstimos junto as instituições de fomento como o BNDES, por exemplo, se comparado as 
empresas não conectadas politicamente (GRAY; HILLMAN, 2005; CHEN et al., 2011; OZER; ALAKENT, 2012; BAZUCHI et al., 2013; BREY et al., 2014; ZHU; CHUNG, 2014; HARYMAWAN; NOWLAND, 2016). Nessa perspectiva, as conexões políticas podem trazer benefícios para a empresa.

No entanto, existem pesquisas que divergem desse pressuposto, mostrando que os custos atrelados as conexões podem ser maiores que os retornos gerados, o que tornaria a iniciativa desvantajosa (BREY et al., 2014; OZER; ALAKENT, 2012). Mesmo que nos últimos anos a democracia e os vários tipos de sistemas econômicos tenham crescido, e tenha se verificado uma melhora nos mecanismos de controle e ampliação da transparência dos atos públicos e privados, ainda existem problemas como o nepotismo, o clientelismo e outros mecanismos informais (BAZUCHI et al., 2013). Assim, tais fatos podem provocar problemas, uma vez que os políticos são financiados por organizações que possuem objetivos diferentes dos de um político em seu papel de governante.

De acordo com Amore e Bennedsen (2013), o benefício das conexões políticas está no controle que os governantes possuem na implementação dos orçamentos, e, nesse processo, fazem uso de sua discricionariedade para administrar as despesas públicas, possibilitando o favorecimento das empresas conectadas. Desta forma, se o ambiente institucional dos países não for plenamente transparente, as empresas podem fazer uso dessa vantagem decorrente de suas conexões políticas a favor da expansão do seu desempenho.

Em tese, as conexões políticas acabam por gerar benefícios mútuos, sendo capaz de envolver grandes quantidades de recursos, diferenciando, conforme a empresa, ou grupo de interesse. A intensidade em que se dá o estreitamento político, fortalece certo grau de comprometimento entre as partes interessadas, podendo ser do político ou do partido, com o retorno esperado por meio de favorecimentos. Os beneficiários passam a possuir um determinado valor que pode ser materializado em informação, influência, proteção, recursos financeiros, rendas governamentais, favorecimento político e outros (AGRAWAL; KNOEBER, 2001).

Ao realizar investimentos na relação com o governo, é possível que algumas empresas esperem obter certos resultados, que podem ser observados por meio de devolução de favores, prestação de serviços, contratos, informações privilegiadas e outras vantagens. Essas expectativas justificam os gastos expressivos disponibilizados à políticos em campanhas eleitorais (SAMUELS, 2001). Nesse sentido, alguns estudos (YEH et al., 2013; SAEED et al., 2015; LIEDONG-RAJWANI, 2017) têm evidenciado que as conexões políticas permitem às empresas terem acesso a empréstimos bancários (por exemplo) com maior facilidade.

A análise do custo da dívida das empresas politicamente conectadas vem despertando, cada vez mais, o interesse dos pesquisadores. Todavia, na literatura, ainda predominam estudos que tem por base empresas localizadas em outras realidades econômicas diferentes do Brasil. Como exemplos, podem ser citados os estudos de Bliss e Gul (2012) que analisaram a associação entre conexões políticas e o custo do financiamento da dívida em empresas da Malásia, Boubakri et al. (2012) que examinaram tal relação em um conjunto de empresas em 26 países diferentes, sendo: Bélgica, Canadá, Dinamarca, Finlândia, França, Alemanha, Hong Kong, Hungria, Indonésia, Irlanda, Itália, Japão, Coréia do Sul, Malásia, México, Países Baixos, Filipinas, Portugal, Cingapura, Espanha, Suécia, Suíça, Taiwan, Tailândia, Reino Unido e Estados Unidos, também Borisova et al. (2015) que investigaram empresas localizadas na América do Norte e Ásia, Shailer e Wang (2015) que analisaram empresas Chinesas e Liedong e Rajwani (2017) que investigaram empresas de Gana. Porém, é um tema que também apresenta lacunas, quando se trata do Brasil. 


\section{ESTUDOS ANTERIORES SOBRE CONEXÕES POLÍTICAS E CUSTO DA DÍVIDA}

Para a seleção dos estudos desta subseção, foram consultados os periódicos internacionais, da área de contabilidade, classificados com índice de alto impacto pelo Journal Citation Reports (JCR), edição 2016. Também foram consultados periódicos nacionais listados no Webqualis da Coordenação de Aperfeiçoamento de Pessoal de Nível Superior (CAPES) (Quadriênio 2013-2016), nos estratos A1 a B5, da área de Administração Pública e de Empresas, Ciências Contábeis e Turismo. Por fim, consultou-se a Biblioteca Digital Brasileira de Teses e Dissertações (BDTD), que integra os sistemas de informação de teses e dissertações existentes nas instituições de ensino e pesquisa do Brasil.

Para identificar as pesquisas, foram realizadas combinações envolvendo as seguintes palavras-chave: political connection; cost of debt e debt financing. Nos periódicos nacionais foram utilizadas as respectivas palavras em português. Assim, inicia-se pela descrição do estudo de Chaney et al. (2011) que analisaram a relação entre qualidade da informação, custo da dívida e conexões políticas, utilizando uma amostra de 7.318 empresas de 21 países. Suas evidências sugeriram que a má qualidade dos resultados não se traduzia em custos de financiamento da dívida mais elevados para as empresas conectadas politicamente, o que implicava que essas empresas não eram penalizadas pelos detentores de debêntures.

Bliss e Gul (2012) investigaram se dualidade no cargo de CEO e de presidente do conselho e a proporção de conselheiros independentes no comitê de auditoria apresentavam impacto no custo da dívida das empresas conectadas politicamente. Analisaram dados de 1.667 empresas da Bolsa de Valores de Kuala Lumpur, na Malásia, de 2001 a 2004. Verificaram que as taxas de juros cobradas das empresas com conexões políticas eram significativamente maiores do que as cobradas em empresas sem conexões. Também, constataram que a dualidade, em empresas com conexões políticas, estava associada a taxa de juros mais altas, enquanto que uma maior proporção de membros independes no comitê de auditoria estava associada a juros mais baixos.

Boubakri et al. (2012) analisaram uma amostra multinacional de 1.248 empresas conectadas e não conectadas politicamente de 26 países nos anos de 1997 a 2001. Encontraram que empresas com conexões políticas possuíam menor custo de capital. Verificaram também que empresas mais antigas e maiores se beneficiavam mais com suas conexões políticas. Destacaram que os investidores valorizavam empresas com conexões políticas, para as quais atribuíam menores custos de financiamento de capital.

Houston et al. (2014) analisaram se as conexões políticas afetavam o custo e os termos dos contratos de empréstimo das empresas listadas nos Estados Unidos. Investigaram um conjunto de dados das empresas do S\&P 500 durante o período 2003 a 2008. Identificaram que o custo dos empréstimos bancários era significativamente menor para as empresas que possuíam membros do conselho com laços políticos. Os resultados demonstraram que as conexões políticas reduziam a probabilidade de uma restrição de gastos de capital ou exigência de liquidez por parte dos bancos na origem do empréstimo.

Borisova et al. (2015) investigaram o impacto das conexões políticas sobre o custo da dívida corporativa. Foram considerados juros anuais para títulos de ações negociados publicamente e dados de propriedade acionária no período de 1991-2010. A amostra final consistiu em 226 empresas de 43 países. Os resultados indicaram que a participação do governo estava associada a um aumento no custo da dívida durante os anos em que não houve crise. Porém, durante a crise financeira, a propriedade do governo estava associada a menores juros.

Shailer e Wang (2015) investigaram o impacto das conexões políticas sobre o custo da dívida das empresas listadas chinesas, comparando diferentes tipos de acionistas controladores 
finais. Utilizaram como amostra todas as empresas listadas chinesas com financiamento e dados disponíveis no período de 2002 a 2008. Os resultados demonstraram que empresas controladas pelo governo tem maior concentração de propriedade, menor dualidade de CEO, maior independência do conselho de administração, mais disponibilidade de fluxo de caixa e maior eficiência. Em geral, os resultados indicaram que as empresas sob controle do governo geralmente têm um menor custo da dívida do que as empresas sob controle privado.

Silva (2016) verificou a influência das conexões políticas, por meio do valor doado para as campanhas eleitorais, no custo de capital de terceiros e no desempenho das empresas brasileiras. A análise ocorreu em uma amostra composta por 3.388 empresas brasileiras no período de 1998 a 2015. O autor não encontrou relações significantes, seja na relação entre as conexões políticas e o custo da dívida, quanto entre conexões e o desempenho.

Liedong e Rahwani (2017) examinaram o impacto das conexões políticas no custo da dívida em Gana, por meio da análise em uma amostra de 179 empresas. As descobertas mostraram uma relação positiva entre os laços políticos e o custo da dívida, que se tornava mais pronunciada quando as empresas conectadas faziam empréstimos de bancos privados e mais fracas quando efetuam empréstimos a bancos de propriedade do governo.

Santos (2017) analisou o efeito das conexões políticas, mensuradas por meio da estrutura de propriedade, conselho de administração e doações para campanhas eleitorais, sobre o custo da dívida. A análise foi composta por um conjunto de 233 companhias abertas listadas na Bolsa de Valores brasileira, no período de 2010 a 2015. Os resultados revelaram que as empresas que mantinham em sua estrutura acionária o governo como acionista direto apresentavam um custo da dívida inferior.

Depreende-se a partir dos artigos apresentados que as conexões políticas das empresas são operações que podem influenciar no custo do endividamento. Porém, ao mesmo tempo, evidenciam que não existe consenso sobre os efeitos dos laços políticos no custo da dívida. Sendo assim, é possível perceber que alguns autores constataram que as conexões políticas reduziam o custo do endividamento, enquanto outros autores verificaram que a influência é para o aumento do custo. Então, estudos empíricos vêm merecendo a atenção de pesquisadores no sentido de analisar a natureza desses laços e seus efeitos. Nota-se, ainda, que na maioria dos estudos apresentados, as investigações ocorreram em empresas americanas, da Indonésia, China, França, Gana, além de outros países, principalmente europeus e asiáticos. Deste modo, o assunto merece atenção em outros países, como no caso do Brasil.

\section{PROCEDIMENTOS METODOLÓGICOS}

Para atender ao objetivo proposto realizou-se pesquisa descritiva, documental e quantitativa. A população compreendeu todas as companhias abertas listadas na B3 que constavam na lista, consultada em 31 de dezembro de 2017, disponibilizada pela instituição. Para definição da amostra, foram excluídas as empresas do setor financeiro em todos os anos investigados, devido às peculiaridades do setor, assim como ocorreu nos estudos similares de Bliss e Gul (2012), Boubakri et al. (2012), Borisova et al. (2015), Shailer e Wang (2015), Silva (2016), Liedong e Rajwani (2017) e Santos (2017). Também foram excluídas as empresas que não dispunham de todas as informações necessárias para os cálculos de todas as variáveis pesquisadas. Após a filtragem necessária, a amostra final foi constituída de 204 (duzentas e quatro) companhias abertas para o ciclo político nacional completo de 2011 a 2014 e 213 (duzentas e treze) companhias para o ciclo político parcial de 2015 a 2016.

É importante esclarecer que diversos estudos, como os de Boubakri et al. (2012), Shailer e Wang (2015) e Liedong e Rajwani (2017), relatam que as conexões políticas existentes no 
ano eleitoral influenciam nas práticas gerenciais das empresas nos anos seguintes, após as eleições. Então, neste estudo, foram verificadas as conexões políticas existentes no ano de 2010 e a influência no custo da dívida do período de 2011 a 2014 e das conexões políticas existentes no ano de 2014 no custo da dívida do período de 2015 a 2016. Por isso, a amostra de pesquisa analisada foi composta por 204 companhias no período de 2011 a 2014 e 213 companhias no período de 2015 a 2016. Logo, os dados de conexões políticas se referem aos anos de 2010 e 2014 , enquanto que os dados de custo da dívida e das variáveis de controle se referem ao período de 2011 a 2016.

Para identificar as empresas que possuíam conexões políticas, inicialmente, criou-se uma variável categórica denominada de doação para campanha eleitoral (Doacao), que recebeu valor " 1 " nos casos em que a companhia havia realizado doações para campanha no ano de 2010 ou 2014 e valor "0" caso contrário. Procedimento similar foi adotado nos estudos de Costa, Bandeira-de-Melo e Marcon (2013), Macêdo, Silva e Machado (2015) e Pinheiro, De Luca e Vasconcelos (2016).

Em seguida, para identificar a participação acionária do governo criou-se uma variável categórica denominada de participação acionária do governo (Particip_Acion), que recebeu valor "1" nos casos em que havia participação acionária (ações ordinárias) do governo (Estado, Município ou União) de, no mínimo, 10\% no ano de 2010 ou 2014 e valor "0" caso contrário. A adoção desse critério é similar à adotada em outros estudos anteriores como os de Boubakri et al. (2012); Borisova et al. (2015); Shailer e Wang (2015) e Liedong e Rajwani (2017).

Por fim, no caso da terceira variável, criou-se uma variável categórica denominada de "Doacao_PartAcion" para os casos em que havia doação para campanha eleitoral ou participação acionária do governo no ano de 2010 ou 2014, seja de forma direta ou indireta, nas empresas da amostra.

No caso das doações para campanhas eleitorais, os dados foram coletados no sítio www.asclaras.org.br e no sítio www.tse.jus.br. Quanto a participação acionária do governo, os dados foram coletados nos Formulários de Referência das companhias, mais especificamente, nas seções 6, 8 e 15. Em relação à variável Doacao_PartAcion que considera a existência de qualquer um dos dois tipos de conexões políticas, os dados foram obtidos nos sítios www.asclaras.org.br e www.tse.jus.br, bem como, nos Formulários de Referência.

Para mensurar o custo de financiamento da dívida, em conformidade com estudos anteriores (BLISS; GUL, 2012; SHAILER; WANG, 2015; FONSECA; SILVEIRA, 2016; SILVA, 2016; LIEDONG; RAJWANI, 2017; SANTOS, 2017), foi efetuado o cálculo da razão entre as despesas financeiras e o passivo oneroso médio do ano. O passivo oneroso corresponde aos empréstimos e financiamentos de curto e longo prazo, incluindo no cálculo as debêntures emitidas. Os dados foram coletados no banco de dados Economática e referem-se ao período de 2011 a 2016.

Em um primeiro momento, foi realizada a análise descritiva das variáveis de conexões políticas e do custo do endividamento. Posteriormente, foi realizado o Teste-t de Student para comparação das médias encontradas de custo do endividamento entre o grupo de empresas que possuíam conexões políticas e o grupo que não possuía conexões políticas. Ressalta-se que foram observados os pressupostos de normalidade dos dados, por meio do teste de KolmogorovSmirnov; e homogeneidade de variâncias, por meio do teste de Levene.

Após, para verificar a influência das conexões políticas no custo da dívida, foi executada análise de regressão por mínimos quadrados ordinários com erro padrão robusto. Cabe destacar que o teste de Pesarán-Pesarán foi aplicado para examinar a existência de homocedasticidade no comportamento dos resíduos. A realização deste teste implicou em regredir o quadrado dos 
resíduos padronizados (Zre_2) como função do quadrado dos resíduos estimados padronizados (Zpr_2). O teste rejeitou a hipótese nula de homocedasticidade. Por essa razão foi estimada a regressão por mínimos quadrados ordinários com erro padrão robusto. Também foi aplicado o teste de Kolmogorov-Smirnov para observar os pressupostos de normalidade. A multicolinearidade foi verificada por meio do fator de inflação de variância e a ausência de autocorrelação por meio do teste de Durbin-Watson.

Neste caso, a variável de custo do financiamento da dívida foi classificada como dependente. As variáveis de conexões políticas, assim como as de controle, foram classificadas como independentes. As variáveis de controle utilizadas foram: endividamento (Passivo circulante + Passivo não circulante / Ativo total), tamanho da empresa (Logaritmo natural do ativo total), ROA (Ebitda/Ativo total), MTB (valor de mercado / patrimônio líquido) e crescimento das vendas (Variação do total das vendas do ano $\mathrm{t}-1$ para $\mathrm{o}$ ano $\mathrm{t}$ ).

a) Endividamento: Empresas com níveis mais elevados de endividamento possuem probabilidade maior de falência e, consequentemente, tornam-se mais propensas a pagar juros mais elevados por serem vistas como mais arriscadas (BLISS; GUL, 2012; BOUBAKRI et al., 2012; BORISOVA et al., 2015; SHAILER; WANG, 2015; SANTOS, 2017).

b) Tamanho da empresa: Empresas maiores terão menor risco de inadimplência se o aumento de tamanho fornecer economias de escala e escopo. Também apresentam capacidade superior para suportar o impacto de desempenhos negativos nos fluxos de caixa e, portanto, são menos propensas à inadimplência. Logo, são vistas como menos arriscadas pelos credores e tendem a ter menores custos de financiamento da dívida (BLISS; GUL, 2012; BORISOVA et al., 2015; LIEDONG; RAJWANI, 2017; SANTOS, 2017).

c) ROA e market-to-book: Empresas com índices mais elevados de ROA e Market-toBook (MTB) tendem a apresentar menor dificuldade para o pagamento das dívidas, ou seja, apresentar menor risco de inadimplência e, consequentemente, conseguirão financiamentos custo inferior (BOUBAKRI et al., 2012; BORISOVA et al., 2015; SHAILER; WANG, 2015).

d) Crescimento das vendas: Empresas em crescimento também são vistas como mais arriscadas, em razão da possibilidade de haver maior instabilidade, variações nos fluxos de caixa, necessidade de investimentos arriscados para manter o crescimento e assimetria de informações que elevam o risco. Então, tendem a apresentar maiores custos de endividamento (BLISS; GUL, 2012; SHAILER; WANG, 2015; LIEDONG; RAJWANI, 2017).

Os dados das variáveis de controle foram extraídos do banco de dados Economática para o período investigado.

\section{DESCRIÇÃO E ANÁLISE DOS DADOS}

Esta seção contém a descrição e análise dos dados coletados. Inicialmente apresentamse os resultados do Teste-t de Student, que permitem a comparação das médias do custo da dívida entre empresas com e sem conexões políticas. Após, apresentam-se os coeficientes das regressões que possibilitam analisar a influência das conexões políticas no custo da dívida.

Os resultados expostos na Tabela 1 permitem verificar se as diferenças no custo da dívida entre o grupo de empresas que realizou doações e o grupo que não realizou são estatisticamente significativas. 
Tabela 1 - Teste de médias do custo do endividamento no período de 2011 a 2016 entre o grupo de empresas que realizou doações e o grupo que não realizou doações

\begin{tabular}{|c|c|c|c|c|c|c|}
\hline \multirow{3}{*}{ Período } & \multicolumn{4}{|c|}{ DOAÇÕES POLÍTICAS } & \multirow{2}{*}{\multicolumn{2}{|c|}{ Teste-t }} \\
\hline & \multicolumn{2}{|c|}{ SIM } & \multicolumn{2}{|c|}{ NÃO } & & \\
\hline & $\begin{array}{c}\mathrm{N}^{\mathrm{o}} \\
\text { Empresas }\end{array}$ & $\begin{array}{c}\text { Médias } \\
\text { custo da dívida }\end{array}$ & $\begin{array}{c}\mathrm{N}^{\mathbf{o}} \\
\text { Empresas }\end{array}$ & $\begin{array}{c}\text { Médias } \\
\text { custo da dívida }\end{array}$ & $\mathbf{t}$ & Sig \\
\hline 2015 a 2016 & 102 & 0,25 & 324 & 0,39 & $-4,14$ & $\mathbf{0 , 0 0}$ \\
\hline 2016 & 51 & 0,25 & 162 & 0,39 & $-4,26$ & $\mathbf{0 , 0 0}$ \\
\hline 2015 & 51 & 0,26 & 162 & 0,39 & $-3,47$ & $\mathbf{0 , 0 0}$ \\
\hline 2011 a 2014 & 220 & 0,22 & 596 & 0,29 & $-2,15$ & $\mathbf{0 , 0 3}$ \\
\hline 2014 & 55 & 0,21 & 149 & 0,37 & $-5,03$ & $\mathbf{0 , 0 0}$ \\
\hline 2013 & 55 & 0,22 & 149 & 0,32 & $-2,96$ & $\mathbf{0 , 0 0}$ \\
\hline 2012 & 55 & 0,20 & 149 & 0,28 & $-2,61$ & $\mathbf{0 , 0 1}$ \\
\hline 2011 & 55 & 0,26 & 140 & 0,25 & 0,26 & 0,80 \\
\hline
\end{tabular}

Fonte: dados da pesquisa

No tocante às doações, conforme Tabela 1, em ambos os anos eleitorais investigados, as empresas que não efetuaram doações são de maior número, mostrando que a prática de doações não é corriqueira nas empresas da amostra, sendo que os percentuais de empresas que fizeram doações nos anos verificados estão próximos a 25\% e não apresentam grande variação.

Os resultados do Teste-t de Student indicaram que as médias do custo do endividamento são estatisticamente diferentes em, praticamente, todos os anos. No primeiro ciclo eleitoral de 2011 a 2014, somente no ano de 2011 as médias não podem ser consideradas diferentes. Todavia, quando se comparam as médias, considerando os dados de todo o período de 2011 a 2014, o custo médio da dívida das companhias que realizaram doações, equivalente a 0,22, é significativamente inferior ao custo médio de 0,29 das que não realizaram doações.

No segundo ciclo político, tanto no ano de $2015(0,26)$, quanto no ano de $2016(0,25)$, as médias de custo da dívida também foram significativamente inferiores no grupo de empresas que realizaram doações. Consequentemente, o mesmo ocorre quando se comparam as médias, considerando os dados do período de 2015 a 2016.

De modo geral, os resultados estão alinhados aos de Shailer e Wang (2015), Borisova et al. (2015), Houston et al. (2014) e Boubakri et al. (2012) que também identificaram indicadores de custo da dívida inferiores em companhias que realizaram doações para campanhas eleitorais. Silva (2016), baseado em autores como Samuel (2001) e Bandeira-deMello e Marcon (2011), destaca que, no contexto brasileiro, as doações podem ser consideradas a medida mais direta e objetiva de conexão política. Isso porque, segundo eles, as doações para campanhas são uma maneira de "comprar" a conexão política e que dessa forma, a relação fica clara, sendo que o político recebe o dinheiro e a empresa ganha o favor.

Para verificar se as diferenças no custo da dívida entre o grupo de empresas que possuem participação acionária do governo e o grupo que não possui, são estatisticamente significativas, calculou-se o Teste-t. Os resultados são apresentados na Tabela 2.

Nota-se na Tabela 2, novamente, que há um número maior de companhias abertas que não possuem participação acionária do governo em sua estrutura de propriedade. Adicionalmente, percebe-se que os valores ficaram praticamente inalterados de um ano para outro, mantendo-se os mesmos percentuais, em torno de $11 \%$ de empresas com participação do governo. 
Tabela 2 - Teste de médias do custo do endividamento no período de 2011 a 2016 entre o grupo de empresas que possuem participação e o grupo que não possui participação acionária

\begin{tabular}{|c|c|c|c|c|c|c|}
\hline \multirow{3}{*}{ Período } & \multicolumn{4}{|c|}{ PARTICIPAÇÃO ACIONÁRIA } & \multirow{2}{*}{\multicolumn{2}{|c|}{ Teste-t }} \\
\hline & \multicolumn{2}{|r|}{ SIM } & \multicolumn{2}{|c|}{ NÃOO } & & \\
\hline & $\begin{array}{c}\mathbf{N}^{\mathbf{0}} \\
\text { Empresas }\end{array}$ & $\begin{array}{c}\text { Médias } \\
\text { custo da dívida }\end{array}$ & $\begin{array}{c}\mathrm{N}^{\mathbf{0}} \\
\text { Empresas }\end{array}$ & $\begin{array}{c}\text { Médias } \\
\text { custo da dívida }\end{array}$ & $\mathbf{t}$ & Sig \\
\hline 2015 a 2016 & 48 & 0,34 & 378 & 0,36 & $-0,39$ & 0,70 \\
\hline 2016 & 24 & 0,32 & 189 & 0,36 & $-0,62$ & 0,54 \\
\hline 2015 & 24 & 0,35 & 189 & 0,36 & $-0,14$ & 0,89 \\
\hline 2011 a 2014 & 92 & 0,28 & 724 & 0,27 & 0,34 & 0,74 \\
\hline 2014 & 23 & 0,37 & 181 & 0,32 & 0,89 & 0,38 \\
\hline 2013 & 23 & 0,28 & 181 & 0,30 & $-0,41$ & 0,68 \\
\hline 2012 & 23 & 0,26 & 181 & 0,26 & $-0,03$ & 0,97 \\
\hline 2011 & 23 & 0,220 & 181 & 0,26 & $-0,85$ & 0,40 \\
\hline
\end{tabular}

Fonte: dados da pesquisa

É possível observar ainda, na Tabela 2, quando se comparam as médias do custo da dívida do grupo das empresas que possuíam participação acionária do governo com o grupo de empresas que não possuíam tal participação, que as médias não são estatisticamente diferentes em nenhum dos anos investigados. O que implica dizer que o custo da dívida não pode ser considerado diferente entre os dois grupos investigados.

Nesse caso, os resultados estão alinhados aos de pesquisadores como Bliss e Gul (2012), Borisova et al. (2015) e Liedong-Rajwani (2017) que também constataram que os indicadores do custo da dívida não eram inferiores em companhias em que o governo possuía participação acionária. Uma justificativa, segundo Liedong e Rajwani (2017), é que os credores da dívida podem perceber que as empresas conectadas por meio de participação acionária são arriscadas, uma vez que sustentar laços políticos pode ser dispendioso, principalmente quando as empresas precisam retribuir favores por meio de apoio a programas sociais do governo, fazer agrados ou dar presentes a políticos, ou mesmo por empregarem pessoas menos capacitadas, por exemplo.

Na Tabela 3, evidenciam-se os resultados do Teste-t: a) das empresas que realizaram doações ou que possuíam participação acionária do governo; b) das empresas que não realizaram doações e nem possuíam participação acionária do governo; e, c) da amostra total.

Tabela 3 - Teste de médias do custo do endividamento no período de 2011 a 2016 entre o grupo de empresas que realizaram doações ou possuíam participação e o grupo das empresas que não realizaram doações ou não possuíam participação acionária

\begin{tabular}{|c|c|c|c|c|c|c|}
\hline \multirow{3}{*}{ Período } & \multicolumn{4}{|c|}{ DOAÇÕES OU PARTICIPAÇÃO ACIONÁRIA } & \multirow{2}{*}{\multicolumn{2}{|c|}{ Teste-t }} \\
\hline & \multicolumn{2}{|c|}{ SIM } & \multicolumn{2}{|c|}{ NÃO } & & \\
\hline & $\begin{array}{c}\mathrm{N}^{\mathrm{o}} \\
\text { Empresas }\end{array}$ & $\begin{array}{c}\text { Médias } \\
\text { custo da dívida }\end{array}$ & $\begin{array}{c}\mathrm{N}^{\mathbf{0}} \\
\text { Empresas }\end{array}$ & $\begin{array}{c}\text { Médias } \\
\text { custo da dívida }\end{array}$ & $\mathbf{t}$ & Sig \\
\hline 2015 a 2016 & 150 & 0,28 & 276 & 0,40 & $-3,51$ & $\mathbf{0 , 0 0}$ \\
\hline 2016 & 75 & 0,27 & 138 & 0,40 & $-3,81$ & $\mathbf{0 , 0 0}$ \\
\hline 2015 & 75 & 0,29 & 138 & 0,40 & $-2,87$ & 0,01 \\
\hline 2011 a 2014 & 312 & 0,24 & 504 & 0,29 & $-1,84$ & $\mathbf{0 , 0 7}$ \\
\hline 2014 & 78 & 0,26 & 126 & 0,37 & $-3,35$ & $\mathbf{0 , 0 0}$ \\
\hline 2013 & 78 & 0,24 & 126 & 0,33 & $-2,78$ & 0,01 \\
\hline 2012 & 78 & 0,22 & 126 & 0,28 & $-2,28$ & $\mathbf{0 , 0 2}$ \\
\hline 2011 & 78 & 0,25 & 126 & 0,26 & $-2,83$ & 0,78 \\
\hline
\end{tabular}

Fonte: dados da pesquisa 
A Tabela 3 permite observar que os percentuais de empresas com conexões políticas existentes, quando considerado qualquer um dos dois tipos de conexões, seja doações para campanhas políticas ou participação acionária do governo, ficaram entre $35 \%$ e $38 \%$. Nesse sentido, em razão de terem sido identificadas, nesta pesquisa, diversas empresas que possuem conexões políticas, fica evidente a importância de investigar essa questão.

É possível perceber ainda, na Tabela 3, ao comparar os dois grupos, que as médias do custo da dívida do primeiro grupo, das empresas que possuíam conexões políticas, são estatisticamente inferiores às médias do segundo grupo, na maioria dos anos. A única exceção ocorre no ano de 2011. Inclusive quando se comparam as médias de todo o período de 2011 a $2014(0,24$ e 0,29) e de todo o período de 2015 a 2016 (0,28 e 0,40). Assim, depreende-se que as empresas que possuem conexões políticas possuem menor custo de financiamento da dívida no ciclo político de 2011 a 2014 e no ciclo político de 2015 a 2016.

Sendo assim, os resultados novamente estão alinhados aos de Shailer e Wang (2015), Borisova et al. (2015), Houston et al. (2014) e Boubakri et al. (2012) que também identificaram indicadores de custo da dívida inferiores em companhias que possuíam conexões políticas.

Na Tabela 4 estão expostos os coeficientes das regressões da influência das conexões políticas no custo da dívida das companhias da amostra. Ressalta-se que as regressões expostas na Tabela 4 foram obtidas a partir dos dados de todo o período, de todas as companhias da amostra.

Tabela 4 - Coeficientes da regressão da influência das conexões políticas no custo do endividamento das companhias abertas listadas na B3

\begin{tabular}{|c|c|c|c|c|}
\hline \multirow{2}{*}{ Variáveis } & \multicolumn{4}{|c|}{ Custo_Div } \\
\hline & Modelo 1 & Modelo 2 & Modelo 3 & Modelo 4 \\
\hline (Constante) & $0,64 * * *$ & $0,65 * * *$ & $0,59 * * *$ & $0,64 * * *$ \\
\hline Doação & $-0,11 * * *$ & & & $-0,11 * * *$ \\
\hline Particp_Acion & & 0,04 & & 0,02 \\
\hline Doacao_PartAcion & & & $-\mathbf{0 , 0 8} * * *$ & $-0,08 * * *$ \\
\hline Endividamento & 0,00 & $-0,02$ & 0,01 & $\mathbf{0 , 0 1}$ \\
\hline Tamanho & $-0,47 * *$ & $-0,51 * * *$ & $-0,39 * *$ & $-0,46 * * *$ \\
\hline ROA & 0,00 & 0,00 & 0,00 & $\mathbf{0 , 0 0}$ \\
\hline MTB & $-0,01 * *$ & $-0,01 * *$ & $-0,01 *$ & $-0,01 * *$ \\
\hline Crescim & $0,02 * * *$ & $0,01 * * *$ & $0,02 * * *$ & $0,02 * * *$ \\
\hline R-quadrado ajustado & 0,30 & 0,22 & 0,27 & 0,30 \\
\hline F-Anova & $6,50 * * *$ & $3,52 * * *$ & $5,27 * * *$ & $5,56 * * *$ \\
\hline VIF/Tolerance & $<10$ & $<10$ & $<10$ & $<10$ \\
\hline Durbin Watson & 1,87 & 1,91 & 1,91 & 1,89 \\
\hline
\end{tabular}

*** Significativo a 1\%;** Significativo a 5\%; * Significativo a $10 \%$.

Fonte: dados da pesquisa.

Nota-se na Tabela 4 que os R-quadrados ajustados ficaram entre $22 \%$ e $30 \%$. Estes Rquadrados ajustados são similares aos registrados em outras pesquisas anteriores da mesma natureza, tais como de Bliss e Gul (2012), que possuíam regressões com $\mathrm{R}^{2}$ de $11 \%$ e $12 \%$, de Boubakri et al. (2012) com $\mathrm{R}^{2}$ de $20 \%$ e $32 \%$ e Liedong-Rajwani (2017) que possuíam $\mathrm{R}^{2}$ de $23 \%$ e $26 \%$, por exemplo. Deste modo, os percentuais explicados pelas variáveis independentes podem ser considerados aceitáveis.

Verifica-se que os testes F-ANOVA foram significantes $(0,01)$, isto é, o conjunto de variáveis independentes exercem influência sobre as variáveis dependentes em todos os 
modelos. Os resultados das estatísticas de Durbin-Watson (entre 1,87 e 1,91) demonstraram que não existem problemas de autocorrelação dos resíduos, já que os valores ficaram próximos de dois. Verifica-se também que o fator de inflação de variância - VIF e Tolerance apresentaram valores baixos $(<10)$. O que implica dizer que nesse caso não existem problemas de multicolinearidade entre as variáveis independentes desse modelo.

Percebe-se ainda, na Tabela 4, que a variável "Doacao", que identifica as empresas que efetuaram doações para campanhas eleitorais, apresentou coeficiente negativo $(-0,11)$ no modelo 1, quando analisada de maneira individual, bem como, no modelo 4, quando analisada juntamente com as demais variáveis do estudo. Além disso, o coeficiente apresentou-se estatisticamente significante $(0,01)$, indicando que as doações influenciam na redução do custo de financiamento da dívida das empresas estudadas.

Sendo assim, ao considerar doações como proxy para conexões políticas, os resultados encontram-se alinhados aos de outros pesquisadores, tais como Boubakri et al. (2012), Houston et al. (2014), Borisova et al. (2015) e Shailer e Wang (2015) que também constataram que as conexões políticas podem influenciar na redução do custo de financiamento da dívida das empresas.

No que tange à variável "Particip_Acion", que capta a participação acionária do governo nas empresas, observa-se na Tabela 4 que o coeficiente foi positivo, seja quando analisado no modelo $1(0,04)$, individualmente, ou no modelo $4(0,02)$, quando analisado de forma combinada com as demais variáveis. Contudo, os coeficientes não são estatisticamente significativos. Mas, apesar da falta de significância, os coeficientes positivos dão indícios de influência da participação acionária do governo para um maior custo do endividamento.

Deste modo, ao considerar participação acionária do governo como proxy para conexões políticas, os achados encontram-se alinhados aos de pesquisadores como Bliss e Gul (2012), Borisova et al. (2015), Liedong-Rajwani (2017), que também constataram que as conexões políticas podem influenciar para aumento do custo de financiamento da dívida.

Conforme já descrito, de acordo com Liedong e Rajwani (2017), uma explicação para este resultado é que os credores da dívida podem perceber o risco associado a este tipo de empresas, haja vista que sustentar laços políticos pode ser dispendioso, principalmente quando as empresas precisam retribuir favores por meio de apoio a programas sociais do governo, fazer agrados ou dar presentes a políticos, ou mesmo por empregarem pessoas menos capacitadas, por exemplo.

É possível perceber que a variável "Doacao_PartAcion" que representa as empresas que efetuaram doações ou que possuíam participação acionária, também apresentou coeficientes negativos e estatisticamente significantes, seja quando analisados de forma individual, no modelo 1, ou quando analisada de forma combinada, no modelo 4. Então, estes resultados indicam que a variável Doacao_PartAcion influencia para a redução do custo do endividamento. Outra vez, os resultados encontram-se alinhados aos de Boubakri et al. (2012), Houston et al. (2014), Borisova et al. (2015) e Shailer e Wang (2015) que também constataram que as conexões políticas podem influenciar na redução do custo de financiamento da dívida das empresas.

Nota-se ainda, na Tabela 4, que dentre as variáveis de controle, três apresentaram-se estatisticamente significantes. Trata-se das variáveis "Tamanho" e "MTB" que apresentaram coeficientes negativos e "Crescim" que apresentou coeficientes positivos. De forma contrária, as variáveis "Endividamento" e "ROA" não apresentaram significância estatística.

No caso da variável Tamanho, o resultado está de acordo com os argumentos de autores como Bliss e Gul (2012), Boubakri et al. (2012), Borisova et al. (2015), Shailer e Wang (2015) e Liedong e Rajwani (2017) de que as empresas maiores, por se beneficiarem de economias de 
escala e desempenho estável. Também por possuírem maior capacidade de suportar desempenhos negativos que impactam em seus fluxos de caixa, são vistas como menos arriscadas por seus credores e tendem a apresentar menores custos de endividamento.

Quanto à variável market-to-book, confirmou-se que índices mais elevados desse indicador estão associados a um menor custo da dívida, de modo que uma maior valorização de mercado resulta em maior credibilidade da empresa perante aos credores da dívida, assim como sugerem os estudos de Boubakri et al. (2012); Houston et al. (2014); Borisova et al. (2015); Shailer e Wang (2015).

Em relação ao crescimento que se mostrou positivo, a principal justificativa recai sobre o argumento de que as empresas que se encontram em constante crescimento podem estar sujeitas a um risco maior, e consequentemente, apresentarem maiores custos de endividamento, conforme descrevem Bliss e Gul (2012), Shailer e Wang (2015) e Liedong e Rajwani (2017).

\section{CONSIDERAÇÕES FINAIS}

O objetivo do estudo foi verificar a influência das conexões políticas no custo de financiamento da dívida de companhias abertas listadas na B3. Os resultados revelaram que o custo de endividamento é inferior em empresas que realizaram doações para campanhas eleitorais. De modo geral, os resultados encontrados nesse quesito corroboram com os achados de Shailer e Wang (2015), Borisova et al. (2015), Houston et al. (2014) e Boubakri et al. (2012) que identificaram indicadores inferiores de custo do endividamento em companhias que possuíam conexões políticas.

Quando analisados os custos da dívida das empresas que possuíam participação acionária do governo, os indicadores demostraram que o custo não era inferior nessas organizações. Nesse aspecto, os resultados estão alinhados aos achados de Bliss e Gul (2012), Borisova et al. (2015) e Liedong e Rajwani (2017) que também constataram que os indicadores do custo da dívida não eram inferiores em companhias em que o governo possuía participação acionária.

Ademais, ao considerar empresas que possuíam qualquer um dos dois tipos de conexão política, seja por doação a campanha eleitoral ou por participação acionária do governo, os resultados novamente estão alinhados aos de Shailer e Wang (2015), Borisova et al. (2015), Houston et al. (2014) e Boubakri et al. (2012) que também identificaram indicadores de custo da dívida inferiores em companhias que possuíam conexões políticas.

Por fim, os achados demonstraram que as conexões por meio de doações para campanhas eleitorais causam maior influência para a redução do custo de financiamento da dívida das empresas. Destaca-se que as doações para campanhas eleitorais são uma prática que tem sido relevante na ligação de empresas com membros políticos e tem exercido influências positivas em diversos outros aspectos. Os resultados sugerem que essa ação é indicativa de que as empresas buscam minimizar riscos e incertezas por intermédio de doações em períodos de campanha eleitoral. Assim, as empresas buscam formas variadas de se relacionar com o ambiente político, principalmente pela incerteza do mercado fazendo com que as instituições intensifiquem seus laços.

Independentemente dos cuidados metodológicos e do rigor científico empregado, o estudo apresenta limitações. A primeira limitação, refere-se ao período de análise, pois a pesquisa considerou dois ciclos políticos, que foram compreendidos entre 2010 e 2016, como recorte temporal para a base de dados. Apesar da forma de análise ser longitudinal, pode não observar todos os efeitos das atuações políticas das empresas ou não apresentar nas variáveis todos os efeitos das decisões políticas que são de difícil observação. Convém enfatizar de que 
a amostra utilizada ficou circunscrita às empresas listadas na B3, não incluindo outras organizações que fazem uso de estratégias políticas.

Outro ponto a ser considerado é a utilização de dados secundários, visto que não foram realizadas entrevistas ou aplicação de questionário, por exemplo. Em consequência, as informações encontradas em algum meio, podem não ser totalmente confiáveis. Em decorrência, alguns achados podem ser afetados, necessitando cuidados quanto a generalização dos resultados.

Dessa maneira, recomenda-se que a pesquisa seja ampliada, utilizando-se, inclusive, empresas de capital fechado e ampliando o período temporal da análise, como forma de identificar tendências do custo de financiamento da dívida de organizações conectadas e não conectadas politicamente. Da mesma maneira, pode-se expandir esta pesquisa, verificando as empresas que participam de certames públicos e empresas de setores mais específicos que possuem interesses ou são dependentes de rendas públicas. Contudo, apesar deste estudo apresentar limitações, a temática em voga mostra-se relevante e não ilegítima os resultados encontrados, que podem, também, ser observados como referência para trabalhos futuros.

\section{REFERÊNCIAS}

AGRAWAL, A.; KNOEBER, C. R. Do some outside directors play a political role. The Journal of Law and Economics, v. 44, n. 1, p. 179-198, 2001.

AMORE, M. D.; BENNEDSEN, M. The value of local political connections in a lowcorruption environment. Journal of Financial Economics, v. 110, n. 2, p. 387-402, 2013.

ARDALAN, K. Capital structure theory: reconsidered. Research in International Business and Finance, v. 39, n.1, p. 696-710, 2017.

BANDEIRA-DE-MELLO, R.; MARCON, R. Unpacking firm effects: modeling political alliances in variance decomposition of firm performance in turbulent environments. Brazilian Administration Review, v. 2, n. 1, p. 21-37, 2005.

BAZUCHI, K. R. V.; ZACHARIAS, S. A. S.; BROERING, L. W.; ARREOLA, M. F.; BANDEIRA-DE-MELLO, R. The role of home country political resources for Brazilian multinational companies. Brazilian Administration Review, v. 10, n. 4, p. 415-438, 2013.

BLISS, M. A.; GUL, F. A. Political connection and cost of debt: Some Malaysian evidence. Journal of Banking \& Finance, v. 36, n. 5, p. 1520-1527, 2012.

BOUBAKRI, N.; GUEDHAMI, O.; MISHRA, D.; SAFFAR, W. Political connections and the cost of equity capital. Journal of Corporate Finance, v. 18, n. 3, p. 541-559, 2012.

BORISOVA, G.; MEGGINSON, W. L. Does government ownership affect the cost of debt? Evidence from privatization. The Review of Financial Studies, v.24, n.8, p.2693-2737, 2011.

BORISOVA, G.; FOTAK, V.; HOLLAND, K.; MEGGINSON, W. L. Government ownership and the cost of debt: Evidence from government investments in publicly traded firms. Journal of Financial Economics, v. 118, n. 1, p. 168-191, 2015. 
BREALEY, R. A.; MYERS, S. C.; ALLEN, F. Capital Structure, and Agency Issues. Journal of Applied Corporate Finance, v. 20, n. 4, p. 49-57, 2008.

BREY, N. K.; CAMILO, S. P. O.; MARCON, R.; BANDEIRA-DE-MELLO, R. Conexões políticas das empresas por estruturas de propriedade: uma abordagem do governo como acionista. R. Administração, Contabilidade e Economia, v.11, n.2, p.319-350, 2012.

CAMILO, S. P. O.; MARCON, R.; BANDEIRA-DE-MELLO, R. Conexões políticas das firmas e seus efeitos na performance: uma convergência entre as perspectivas da governança e da dependência de recursos - um ensaio teórico. Revista Alcance, v.19, n.2, p.241-258, 2012.

CHEN, C. J. P.; LI, Z.; SU, X.; SUN, Z. Rent-seeking incentives, corporate political connections, and the control structure of private firms: Chinese evidence. Journal of Corporate Finance, v. 17, n. 2, p. 229-243, 2011.

CLAESSENS, S.; FEIJEN, E.; LAEVEN, L. Political connections and preferential access to finance: the role of campaign contributions. Journal of Financial Economics, v. 88, n. 3, p. 554-580, 2008.

CORREIA, M. M. Political connections and SEC enforcement. Journal of Accounting and Economics, v. 57, n. 2, p. 241-262, 2014.

COSTA, M.; BANDEIRA-DE-MELLO, R.; MARCON, R. Influência da conexão política na diversificação dos grupos empresariais brasileiros. Revista de Administração de Empresas, São Paulo, v. 53, n. 4, p. 376-387, 2013.

DERRIEN, F.; KECSKÉS, A.; MANSI, S. A. Information asymmetry, the cost of debt, and credit events: Evidence from quasi-random analyst disappearances. Journal of Corporate Finance, v. 39, n. 2, p. 295-311, 2016.

DING, R.; LI, J.; WU, Z. Government affiliation, real earnings management, and firm performance: The case of privately held firms. Journal of Business Research, v. 83, n.2, p. 138-150, 2018.

FACCIO, M. Politically connected firms. The American Economic Review, v. 96, n. 1, p. 369-386, 2006.

FISMAN, R. Estimating the value of political connections. American Economic Review, v. 91, n. 4, p. 1095-1102, 2001.

GHOUMA, H.; BEN-NASR, H.; YAN, R. Corporate governance and cost of debt financing: Empirical evidence from Canada. The Quarterly Review of Economics and Finance, v. 67, n. 4, p. 138-148, 2017.

GOLDMAN, E.; ROCHOLL, J.; SO, J. Do politically connected boards affect firm value? The Review of Financial Studies, v. 22, n. 6, p. 2331-2360, 2009. 
GRAY, S.; HILLMAN, A. J. Political and government connections on corporate boards in Australia: Good for business? Australian Journal of Management, v.41, n. 1, p. 3-26, 2016.

HARYMAWAN, I.; NOWLAND, J. Political connections and earnings quality: How do connected firms respond to changes in political stability and government effectiveness? International Journal of Accounting \& Information Management, v. 24, n. 4, p. 339-356, 2016.

HILLMAN, A. J.; KEIM, G. International variation in the business-government interface: institutional and organizational considerations. Academy of Management Review, v. 20, n. 1, p. 193 - 214, 1995.

HILLMAN, A. J.; HITT, M. Corporate political strategy formulation: A model of approach, participation and strategy decisions. Academy of Management Review, v. 20, n.5, p. 193214, 1999.

HOUSTON, J. F.; JIANG, L.; LIN, C.; MA, Y. Political connections and the cost of bank loans. Journal of Accounting Research, v. 52, n. 1, p. 193-243, 2014.

HUNG, C.H.D.; JIANG, Y.; LIU, F. H.; TU, H.; WANG, S. Bank political connections and performance in China. Journal of Financial Stability, v. 32, n.2, p. 57-69, 2017.

JACKOWICZ, K.; KOZLOWSKI, L.; MIELCARZ, P. Political connections and operational performance of non-financial firms: new evidence from Poland. Emerging Markets Review, v. 20, n. 2, p. 109-135, 2014.

LE, T. P. V.; BICH, N. P. T. Capital Structure and Firm performance: Empirical evidence from a developing country. Research in International Business and Finance, v. 10, n. 16, p. 710-726, 2017.

LIEDONG, T. A.; RAJWANI, T. The impact of managerial political ties on corporate governance and debt financing: Evidence from Ghana. Long Range Planning, v. 10, n. 1, p.1-14, 2017.

MAHON, J. F.; MURRAY, E. A., Jr. Strategic planning for regulated companies. Strategic Management Journal, v. 2, n. 3, p. 251-262, 1981.

OZER, M.; ALAKENT, E. The influence of ownership structure on how firms make corporate political strategy choices. Business \& Society, v. 52, n. 3, p. 451-472, 2012.

PEROBELLI, F. F. C.; FAMA, R. Fatores determinantes da estrutura de capital para empresas latino-americanas. Revista de Administração Contemporânea, v. 7, n. 1, p. 9-35, 2003.

PITTMAN, R. Market structure and campaign contributions. Public Choise, v. 31, n.1, p. 37$52,1977$. 
ROSS, S. A.; WESTERFIELD, R. W.; JAFFE; J. F. Corporate Finance: Student Problem Manual for Use with. New York: McGraw-Hill, 2002.

SAEED, A.; BELGHITAR, Y.; CLARK, E. Do Political Connections Affect Firm Performance? Evidence from a Developing Country. Emerging Markets Finance and Trade, v. 52, n. 8, p. 1876-1891, 2015.

SAMUELS, David J. Money, elections, and democracy in Brazil. Latin American Politics and Society, v. 43, n. 2, p. 27-48, 2001.

SANTOS, A. K. A. Custo e ganho da dívida e as conexões políticas: um estudo em empresas listadas na BM\&FBOVESPA. 73 f. 2017. Dissertação de Mestrado. Universidade Federal da Paraíba, 2017.

SENA, A.; BARCELLOS, C.; FREITAS, C.; CORVALAN, C. Managing the health impacts of drought in Brazil. International journal of environmental research and public health, v. 11, n. 10, p. 10737-10751, 2016.

SHAILER, G.; WANG, K. Government ownership and the cost of debt for Chinese listed corporations. Emerging Markets Review, v. 22, n. 1, p. 1-17, 2015.

SILVA, A. L. C.; GRAMINHO, F. M. Campaign finance and corporate governance: the case of Brazil. Corporate Ownership \& Control, v. 3, n. 2, p. 125-136, 2005.

SILVA, J. C. A influência das conexões políticas no custo de capital e no desempenho das empresas brasileiras listadas na BM\&FBOVESPA. 111 f. 2016. Dissertação de Mestrado. Universidade do Sul de Santa Catarina, 2016.

YEH, Y.; SHU, P.; CHIU, S. Political connections, corporate governance and preferential bank loans. Pacific-Basin Finance Journal, v. 21, n. 1, p. 1079-1101, 2013.

ZHU, H.; CHUNG, C. N. Portfolios of political ties and business group strategy in emerging economies: evidence from Taiwan. Administrative Science Quarterly, v. 59, n. 4, p. 599638, 2014. 